\title{
Research on the Influence of COVID-19 on Transportation Industry Based on Fama-French Five Factor Model
}

\author{
Chenyang Peng ${ }^{1, *}$ \\ ${ }^{1}$ Computer Science Department, University of Liverpool, Liverpool L69 7ZX, United Kingdom \\ ${ }^{*}$ Corresponding author. Email: sgcpeng2@liverpool.ac.uk
}

\begin{abstract}
Over the years, the Capital Asset Pricing Model (CAPM) has been continuously improved with the efforts of many researchers. In this study, Fama-French five-factor model, which is excellent in estimating the average stock return, is used for regression analysis. Analyzing the performance of the three transportation sectors (automobile industry, aircraft industry and ship industry) in the market during the period of the COVID-19 can judge the impact of the COVID-19 on the transportation industry. In addition, to analyze whether the government's effective emergency rescue measures issued by various countries help various industries to evade the economic risks brought by COVID19. The results of this paper show that COVID-19 has indeed had a profound impact on the world transportation industry and economic market. More importantly, three research objects in this study were totally seriously affected by COVID-19. On the whole, due to the social alienation policies issued by various countries, the survival threat to the aircraft industry is the most serious. Even though airlines try to take measures to reduce economic losses, there are still large airlines that cannot support their daily operations in the short term and declare bankruptcy. In conclusion, even the most serious period of the COVID-19 crisis is only a few months, and governments of various countries have also allocated funds for rescue to retain some industries. However, the impact on the world economy cannot be recovered in the short term.
\end{abstract}

Keywords: COVID-19, CAPM, Fama-French five-factor model, Transportation industry.

\section{INTRODUCTION}

COVID-19, which broke out in February 2020, swept the world and caused a serious blow to the global economy. This has led to heavy losses for many enterprises. A large number of small and medium-sized enterprises have gone bankrupt, and many employees are facing the risk of unemployment. From the overall market performance, COVID-19 has caused many industries to be in a state of depression. This negative impact is especially serious for the transportation industry, such as road transportation, air transportation and maritime transportation. The government's policy to protect public safety, which led to public transport, suffered a devastating blow quickly. Even many large enterprises cannot support it and go bankrupt one after another. For instance, FLYBE Airlines in the UK declared bankruptcy on March 5, 2020. When the public transport industry is depressed, this serious negative impact is interrelated. Tourism and agricultural transportation are also facing survival challenges. The impact of COVID-19 on the world economy is hard to recover in a short time.

Due to the far-reaching impact of COVID-19 on the world's macroeconomy, many researchers launched a study and discussion on the future economy in the background of the COVID-19 crisis. Fernandes discussed the economic impact of the COVID-19 crisis on different countries and industries. Fernandes first estimated the possible economic cost of COVID-19's crisis and then predicted the growth of GDP in different countries. More, Fernandes discusses the channels that affect economic activities and the asymmetric results of different countries and industries. In general, the economic impact of COVID-19 is almost inevitable [1]. To a certain extent, the economy of every industry is threatened by COVID-19. Most people were in a state of anxiety and panic at the early stage of the outbreak of COVID-19. Fetzer et al. evaluated the impact of the 
rapid emergence of economic anxiety and its causes. Fetzer et al. collected data from the same period to investigate the development and determinants of economic anxiety at the beginning of the COVID-19 pandemic. More, the results of Fetzer et al. show that most people's subjective understanding of COVID-19 and the psychological model of infectious disease transmission great probability cause economic anxiety among the crowd [2].

To protect people's lives, governments of various countries issued social alienation policies in time. Fatmi takes Canada as an example to discuss individual's responses after the launch of COVID-19's travel restrictions and emergencies. Fatmi collects and analyzes the information of respondents worldwide on daily activities, long-distance travel and the number of urban populations. The results show that personal outdoor travel decreased by $50 \%$ compared with the period of COVID-19 before the crisis. Furthermore, $40 \%$ of the respondents would choose to travel by private car if their travel plan is not affected, and about $45 \%$ of the respondents who change their travel plan prefer to travel by air [3]. During the period of COVID19, the travel needs of the disabled become more difficult to achieve. Cochran, to study the impact of COVID-19 on the transportation of persons with disabilities, in-depth interviews with persons with disabilities in the San Francisco Bay area was analyzed. Through sampling and interview data collection, Cochran found that during COVID-19, respondents were more difficult to travel than usual and had to rely more on nursing staff and delivery services. Then, Cochran mentioned that COVID-19 had a devastating blow to public transport, which aggravated the difficulties for disabled people to get access to transportation and other basic services, especially for disabled persons who could not use family vehicles. Finally, Cochran concludes that persons with disabilities may need to rely more on their care networks and social support systems than usual in emergencies [4].

At the same time, COVID-19 has also brought great challenges to the agricultural transport chain. Taking Canada as an example, Gray analyzed the impact of COVID-19 on agricultural supply chain transportation. Analysis shows that under the influence of covid 19, the demand for transportation services in other industries decreased. Even if some supply chain transportation enterprises have labour interruptions, it will not have too much negative impact on the transportation of agricultural products. Gray also mentioned that many transport services are made up of small teams. This makes them more resilient to COVID-19 [5]. Moreover, Hobbs believes COVID-19 has a profound impact on the global macro-economy, and the food supply chain industry is facing enormous challenges of survival. Hobbs analyzed the specific impact of COVID-19 on the agricultural sector and commodity supply chain in
Canada. First, most of the population was panic at the early stage of COVID-19, which made the necessities of supermarket shelves panic buying and hoarding. People's panic buying behavior has caused the supply chain of daily necessities to fall short of demand. The key categories of goods are in short-term shortage, which makes the lives of people with weak mobility difficult. For example, the elderly and the disabled living alone. Secondly, another survival challenge facing the commodity supply chain is the social alienation policy issued by the government. During the lockdown, a large number of restaurants and bars were closed, leading to the risk of bankruptcy of the supply chain enterprises providing food for them. Finally, Hobbs proposes that online grocery distribution services can alleviate people's shopping demand to a certain extent and provide living space for most commodity supply chains [6].

Many managers of enterprises will involve the capital asset pricing model in reference to capital decision-making. Therefore, researchers have conducted in-depth research on CAPM. Dessaint et al. to prove the difference between the implied revenue and the actual revenue of CAPM, a model with participants including bidders, sellers and markets is used for verification. Dessaint et al. believe that CAPM users are willing to buy low beta assets at a price considered too high by the market, while CAPM users are also willing to sell high beta assets at a price considered too low by the market. The results show that enterprises gain strategic significance when applying CAPM to capital budget decision-making [7]. To better prove whether the performance of the capital asset pricing model is better than other models in practical application, Nhleko et al. estimated the equity cost of the project discount rate by comparing the capital asset pricing model and Gordon wealth growth model. First, Nhleko et al. Collected data from six mining companies that grew steadily and paid dividends regularly. Then, through the analysis of descriptive statistics and box charts, Nhleko et al. concluded that CAPM accurately recorded the actual cost of equity during the study period, while Gordon's growth model is more sensitive to the changing trend of WACC's equity part [8].

In previous studies, a large number of researchers compared the three-factor model with the five-factor model. Foye extends previous research by testing alternative specifications for profitability factors. Foye's preliminary test shows that the five-factor model reassigned using gross profit rather than operating profit provides an improved description of UK equity return. However, when evaluated according to different test portfolios, the performance of test factors is inconsistent, and the prices of value and investment premium are also inconsistent. The results of the Foye study show that both the three-factor and five-factor models cannot convincingly describe the return on 
equity in the UK, so they cannot be regarded as a reliable indicator to measure financial risk [9]. Furthermore, to help investors estimate the average stock return of the stock market more effectively, researchers Mosoeu and Kodongo tested the developed stock market with the Fama-French three-factor model and Fama-French five-factor model, respectively. Mosoeu and Kodongo conclude that the change of stock return cross-section cannot be fully explained by the three-factor model, while the performance of the fivefactor model is better than that of the three-factor model. In conclusion, the five-factor model makes up for the three-factor model's defects to a certain extent [10].

This paper takes three transportation industries as the research object, uses the Fama-French five-factor model to analyze the impact of COVID-19's outburst on these three industries by regression analysis of data, and analyzes the causes of these effects and the possible consequences of these effects. More importantly, from an objective point of view, this paper analyzes the survival challenges brought by the social alienation policy for the transportation industry during the period of COVID-19.

\section{METHOD}

In previous studies, some researchers proposed that the CAPM model has defects. Fama and French proposed an alternative to the three-factor model in 1996 [11]. Two unknown state variables were added to the original CAPM model to improve the model.

Compared with the original CAPM model, the threefactor model adds size effect and value effect.

$R_{i}-R_{F}=\beta m k t\left(R_{M}-R_{F}\right)+\beta_{S M B} S M B+\beta_{H M L} H M L+\varepsilon i(1)$

$\mathrm{R}_{\mathrm{M}}$ represents the yield of the market portfolio; $\mathrm{R}_{\mathrm{F}}$ represents the risk-free interest rate in the market; $R_{i}$ represents the expected rate of return of the portfolio $\mathrm{i}$; SMB represents the difference in returns between low market capitalization companies and high market capitalization companies; HML represents the difference value in returns between companies with high Book-to-market ratio and growth companies with low Book-to-market ratio.

By analyzing the evidence provided by other researchers, Fama and French concluded that the threefactor model is an incomplete expected return model. Because the three factors in the three-factor model (1) ignore some changes in average income related to profitability. Therefore, Fama and French proposed a five-factor model in 2005, adding two variables of profitability and investment factors to the three-factor model [12].

$R_{i}-R_{F}=\beta m k t\left(R_{M}-R_{F}\right)+\beta_{S M B} S M B+\beta_{H M L} H M L+$ $\beta_{R M W} R M W+\beta_{C M A} C M A+\varepsilon i$
RMW represents the difference in profitability between companies; CMA represents the difference in returns between companies with different investment levels.

Totally, the Fama-French five-factor model performs better than the three-factor model in explaining the expected return of a cross-sectional stock portfolio.

\section{RESULTS}

The above methods are used to process and analyze the data from May 2019 to February 2020 and from March 2020 to December 2020. These two time periods are divided into before COVID-19 and after COVID-19. In addition, this paper uses multiple linear regression (MLR) to obtain the fitting results of three transportation data.

Table 1. 5-FACTOR REGRESSION of Autos before \& after Covid19

\begin{tabular}{ccccc}
\hline \multirow{2}{*}{ Factor } & \multicolumn{2}{c}{ Before } & \multicolumn{2}{c}{ After } \\
\cline { 2 - 5 } & Coefficient & T-value & Coefficient & T-value \\
\hline MKT-RF & 1.035 & 16.589 & 0.9055 & 25.675 \\
SMB & 0.979 & 8.340 & 1.0084 & 11.099 \\
HML & 0.405 & 3.365 & 0.0309 & 4.1299 \\
RMW & 0.869 & 4.425 & 0.4851 & 3.2027 \\
CMA & -0.17 & -0.732 & -0.2403 & -1.2389 \\
\hline
\end{tabular}

In the regression analysis of Autos data, it can be seen from the $\mathrm{T}$ value that the significance of the five factors before and after the COVID-19 crisis has not changed.

Before COVID-19, only MKT-RF had greater volatility than the market. After COVID-19, the volatility of MKT-RF is less than that of the market, and the volatility of SMB becomes greater than that of the market.

Table 2. 5-FACTOR REGRESSION of Aero before \& after Covid19

\begin{tabular}{ccccc}
\hline Factor & \multicolumn{2}{c}{ Before } & \multicolumn{2}{c}{ After } \\
\cline { 2 - 5 } & Coefficient & T-value & Coefficient & T-value \\
\hline $\begin{array}{c}\text { MKT- } \\
\text { RF }\end{array}$ & 0.9491 & 14.498 & 0.9568 & 14.6103 \\
SMB & 0.2177 & 1.7675 & 0.8192 & 4.8560 \\
HML & 0.0719 & 0.5690 & 0.7353 & 5.2988 \\
RMW & -0.0817 & -0.3969 & 0.3648 & 1.2972 \\
CMA & 0.3578 & 1.4685 & -0.6882 & -1.9104 \\
\hline
\end{tabular}


It can be concluded from the statistical data analysis of the Aero industry, from the $\mathrm{T}$ value, the significance of SMB and HML changed before and after COVID-19. Both of them changed from "not significant" to "significant". The significance of other factors did not change. Furthermore, the volatility of the five factors did not change before and after COVID-19, which was less than that of the market.

Table 3. 5-FACTOR REGRESSION of Ships before \& after Covid19

\begin{tabular}{lllll}
\hline Factor & Before & \multicolumn{3}{l}{ After } \\
\cline { 2 - 5 } & Coefficient & T-value & Coefficient & T-value \\
\hline MKT- & 0.9566 & 11.981 & 0.9170 & 20.2339 \\
RF & & & & \\
SMB & 1.1021 & 7.3346 & 0.9012 & 7.7185 \\
HML & 0.5986 & 3.8847 & 0.4613 & 4.8039 \\
RMW & 0.4712 & 1.8759 & -0.0892 & -0.4582 \\
CMA & -0.201 & -0.6762 & -0.6266 & -2.5134 \\
\hline
\end{tabular}

From the regression analysis of ship industry data, it can be shown that the $\mathrm{T}$ value that the significance of CMA changed before and after the COVID-19 crisis, and its data changed from "not significant" to "significant". The volatility of SMB has changed from greater than the market volatility to less than the market volatility. The volatility of other factors remains unchanged and is less than the market volatility.

\section{DISCUSSION}

After COVID-19 swept the world, governments have issued policies to restrict entry and exit. Although these policies are to protect public safety, they have caused a devastating blow to public transport in a short time. Therefore, this study used Fama-French 5 factor model to analyze the data of three transportation industries before and after COVID-19. Furthermore, it investigated the negative impact of COVID-19 on the transportation industry and analyzed and put forward countermeasures for these impacts.

\subsection{Autos}

Road transportation is the main mode of transportation in cities. With the continuous increase of big cities, urban transportation is becoming more and more important. But COVID-19 has caused a serious blow to public transport in the city, and the public will switch to private cars or walk to protect their own safety. The regression analysis data show that the volatility of MKT-RF in Autos is greater than that in the market before the new crown virus, and the fluctuation of MKT-RF is less than that of the market after the influence of the new crown virus. It can be seen from the statistics that the share price of the automobile industry is lower than the market share, which proves that the outbreak of COVID-19 has brought a lot of economic cost to the auto industry.

When the number of COVID-19 infected continues to rise, and there is no ease, governments have introduced a series of social alienation policies. Limiting the close ties between the masses and mobility of the population can prevent the continuous expansion of the new crown virus [13]. Specific measures include limiting unnecessary links and gatherings, prohibiting meals in restaurants, only taking food away and strict domestic segregation policy [14]. This policy has had a far-reaching impact on macroeconomic development. During the popularity of COVID-19, the food supply chain also suffered a lot of impacts. Specific aspects include the interruption of the transportation network, labour shortage and exit and entry restriction policies issued by various countries. According to the Hobbs study, many workers are ill because of infection with COVID-19. Workers who are in close contact with these sick workers are also restricted to action and are required to isolate themselves, which results in a labour shortage food processing and distribution channels. Hobbs also proposed that in terms of the scale of the food processing chain, most of the food and beverage processing enterprises are small enterprises. Most of the companies responsible for transhipment in the transportation network are also small companies [6]. For instance, according to the 2016 study, $94.1 \%$ of food processing enterprises are small enterprises with less than 100 employees [15]. According to Hobbs, longdistance truck transportation and goods distribution are very easily affected by labour interruption or movement restrictions [6]. For example, due to the scattered population distribution in Canada, the commodity sales chain is very long and very dependent on the normal operation of long-distance road transportation and railway transportation networks.

In general, in the automotive industry, small and medium-sized enterprises can take more measures to deal with the sudden outbreak of COVID-19 than the big enterprises and are more flexible in handling business. But small businesses are more vulnerable to labour disruption.

\subsection{Aero}

Firstly, the SMB factor in the aircraft industry has become significant after COVID-19, and its coefficient is greater than zero. This change shows that the return rate of stocks with small market value is higher than that of stocks with large market value. In addition, this means that after a serious attack by COVID-19, the survival rate of small businesses in the aviation industry is larger than that of large enterprises, and large enterprises are more likely to go bankrupt than small 
ones. Secondly, the HML factor tends to be significant after being influenced by COVID-19, and its coefficient is positive. This shows that value companies with a high Book-to-market ratio have higher returns than growth companies with low Book-to-market ratios. Fama and French [12] believe that companies with a high Bookto-market ratio are more vulnerable than those with a low Book-to-market ratio, so they have higher risks. For example, companies already in financial trouble are more sensitive to changes in their financial position.

The International Air Transport Association (IATA) has forecast that the airline revenue will drop by about $55 \%$ in 2020 compared with 2019. The airlines will lose the total value equivalent to $\$ 314$ billion in 2020 [16]. From March 2020 to April, when COVID-19 had the most serious impact on society, almost all European airlines took emergency measures to minimize losses. For example, most flights are grounded, and layoffs are implemented. Although all airlines have reduced their losses to the greatest extent, some airlines still cannot support their daily operations and declare bankruptcy. For instance, the Flybe airline of the United Kingdom cannot withstand the serious blow brought by the new crown virus and declared bankruptcy on five March 2020 [17].

To sum up, the sudden outbreak of the new crown virus has made the airline industry caught off guard, which has caused serious losses to all airlines. Moreover, because most of the enterprises in the aviation industry are large enterprises, the speed of large enterprises in the face of crisis and the flexibility of business management is not as good as those of small enterprises. Therefore, the loss suffered by the aviation industry during COVID-19 is the most serious in the three transportation industries.

\subsection{Ships}

The statistics of the shipping industry changed little before and after the outbreak of COVID-19. Only the CMA factor changed significantly, but its coefficient remained negative. CMA is a factor in measuring the return difference between companies with low investment levels and companies with high investment levels. Firstly, the negative CMA value shows that investors prefer small-scale enterprises when investing. But on the other hand, it may also be a trap for investors. Secondly, as Railroad Equipment is also included in the shipping industry, the market is relatively scattered. This situation indicates that using the CMA factor to measure the market results may not be very accurate.

The crew of large oceangoing freighters is separated from mainland residents when they are transported by sea, so the crew is not threatened by COVID-19 when they are transported by sea. With the government's policy of social alienation, including port landing restrictions and crew members' fear of bringing COVID-19 to the ship, the crew became more isolated. According to Gray's data analysis, the Baltic Sea freight rate fell by $80 \%$ from September 2019 to February 2020 and then rebounded slightly in the following months [5]. Under the influence of COVID-19, the demand for marine transportation has declined. Crew members not only face a decline in income but also may face the risk of unemployment.

Overall, the demand for transport services in other industries declined during the COVID-19 pandemic, which is beneficial to transferring agricultural products in a special period. The agricultural transport chain does not have to worry about the interruption of a single transport industry network, resulting in the nontransportation of food. What is more important is that the crew members of the shipping industry earn little profits from transporting agricultural products by sea. Still, they are enough to support the crew through the most difficult period of COVID-19.

\section{CONCLUSION}

This study uses the regression analysis method and the Fama-French five-factor model to conduct a market evaluation of the three transportation industries before and after the COVID-19 outbreak. The final conclusion is drawn by the analysis of the impact of COVID-19 on the three transportation industries. In the transportation industry, the impact caused by the interruption of the transportation networks is interrelated. Even if the governments of various countries issued emergency hedging policies in the shortest time, they still could not save most small and medium-sized enterprises or even large enterprises. Generally speaking, COVID-19 has had a profound impact on the world's macroeconomy.

\section{REFERENCES}

[1] Fernandes, N. (2020). Economic Effects of Coronavirus Outbreak (COVID-19) on the World Economy. SSRN Electronic Journal. https://doi.org/10.2139/ssrn.3557504.

[2] Fetzer, T., Hensel, L., Hermle, J., \& Roth, C. (2020). Coronavirus Perceptions and Economic Anxiety. The Review Of Economics And Statistics, 1-36. https://doi.org/10.1162/rest_a_00946.

[3] Fatmi, M. (2020). COVID-19 impact on urban mobility. Journal of Urban Management, 9(3), $270-275$ https://doi.org/10.1016/j.jum.2020.08.002.

[4] Cochran, A. (2020). Impacts of COVID-19 on access to transportation for people with disabilities. Transportation Research Interdisciplinary 
Perspectives, 8 , 100263. https://doi.org/10.1016/j.trip.2020.100263.

[5] Gray, R. (2020). Agriculture, transportation, and the COVID-19 crisis. Canadian Journal of Agricultural Economics/Revue Canadienne D'agroeconomie, 68(2), 239-243. https://doi.org/10.1111/cjag.12235.

[6] Hobbs, J. (2020). Food supply chains during the COVID-19 pandemic. Canadian Journal of Agricultural Economics/Revue Canadienne D'agroeconomie, $\quad$ 68(2), 171-176. https://doi.org/10.1111/cjag.12237.

[7] Dessaint, O., Olivier, J., Otto, C., \& Thesmar, D. (2020). CAPM-Based Company (Mis)valuations. The Review Of Financial Studies, 34(1), 1-66. https://doi.org/10.1093/rfs/hhaa049.

[8] Nhleko, A., \& Musingwini, C. (2016). Estimating cost of equity in project discount rates: comparison of the Capital Asset Pricing Model and Gordon's Wealth Growth Model. Journal Of The Southern African Institute Of Mining And Metallurgy, $116(2)$. https://doi.org/10.17159/24119717/2016/v116n3a1.

[9] Foye, J. (2018). Testing alternative versions of the Fama-French five-factor model in the UK. Risk Management, 20(2), 167-183. https://doi.org/10.1057/s41283-018-0034-3.

[10] Mosoeu, S., \& Kodongo, O. (2020). The FamaFrench five-factor model and emerging market equity returns. The Quarterly Review of Economics And Finance. https://doi.org/10.1016/j.qref.2020.10.023.

[11] Fama, E. (1996). Multifactor Portfolio Efficiency and Multifactor Asset Pricing. The Journal of
Financial And Quantitative Analysis, 31(4), 441. https://doi.org/10.2307/2331355.

[12] Fama, E., \& French, K. (2015). International Tests of a Five-Factor Asset Pricing Model. SSRN Electronic Journal. https://doi.org/10.2139/ssrn.2622782.

[13] Robertson, L. (2021). Predictors of COVID-19Confirmed Cases and Fatalities in 883 US Counties with a Population of 50,000 or More: Estimated Effect of Initial Prevention Policies. Journal Of Urban Health, 98(2), 205-210. https://doi.org/10.1007/s11524-021-00514-5.

[14] Teslya, A., Pham, T., Godijk, N., Kretzschmar, M., Bootsma, M., \& Rozhnova, G. (2020). Impact of Self-Imposed Prevention Measures and Short-Term Government Intervention on Mitigating and Delaying a COVID-19 Epidemic. SSRN Electronic Journal. https://doi.org/10.2139/ssrn.3555213.

[15] Agriculture and Agri-Food Canada (AAFC). (2017). An overview of the Canadian agriculture and agrifood system 2017. Research and Analysis Directorate, Strategic Policy Branch, Agriculture and Agri-Food Canada. Catalogue no. A38-1/1E. AAFC no. 12714E, November.

[16] COVID-19 Puts Over Half of 2020 Passenger Revenues at Risk. Iata.org. (2021). Retrieved 29 August 2021, from https://www.iata.org/en/pressroom/pr/2020-04-1401/.

[17] UK airline Flybe declares bankruptcy as coronavirus dooms the already struggling carrier. Business Insider. (2021). Retrieved 29 August 2021, from https://www.businessinsider.com/ukairline-flybe-declares-bankruptcy-flightsgrounded-2020-3. 